\title{
COUNTERPOINT: Despite staging inaccuracies, patients with non- small cell lung cancer are best served by having integrated positron emission tomography/computed tomography before therapy
}

Robert J. Cerfolio, MD, FACS, FCCP

For related article see page 13 .

We just heard and read an eloquent presentation from Stiles and associates ${ }^{1}$ from New York Hospital. The basic import of their study is that when positron emission tomography (PET) using fluorodeoxyglucose (FDG) scan predicts that a patient has stage IA non-small cell lung cancer (NSCLC), the patient truly has pathologic stage IA disease only $65 \%$ of the time. There are a few concerns about the methodology of this well done study: not all patients received integrated positron emission tomography/computed tomography (PET/ $\mathrm{CT}$ ), which has been shown to be superior in several studies and two prospective studies when compared to dedicated PET. ${ }^{2-4}$ The time interval between the PET scan and the eventual operation is not specified. However, their findings are accurate, honest, and important. Moreover, the results of their study are very similar to a previous study from our group, which was presented at a meeting of The Society of Thoracic Surgeons and published in $2005 .^{5}$ The real question that should be posed is not about the validity of this study's findings but rather about its clinical significance. In this point-counterpoint article, I will focus on the specific results of the article by Stiles and associates ${ }^{1}$ and repeatedly query how the inaccuracy of PET injured patient care. How many patients had their treatment or care misguided by the PET's incorrect prediction? Inasmuch as these patients underwent anatomic pulmonary resection and complete thoracic lymphadenectomy, the answer is few to none. The same question must then be asked if the patient had undergone a less invasive procedure, which may be more commonly chosen in the future.

\footnotetext{
From the Department of Surgery, the Division of Cardiothoracic Surgery, University of Alabama at Birmingham, Birmingham, Ala.

Read at the Eighty-eighth Annual Meeting of The American Association for Thoracic Surgery, San Diego, California, May 10-14, 2008. Presented as part of the Point/ Counterpoint Session in General Thoracic Surgery.

Received for publication June 21, 2008; accepted for publication Aug 29, 2008.

Address for reprints: Robert J. Cerfolio, MD, FACS, FCCP, Professor, Department of Surgery, Chief of Thoracic Surgery, Division of Cardiothoracic Surgery, University of Alabama at Birmingham (UAB), $70319^{\text {th }}$ St S, ZRB 739, Birmingham, AL 35294 (E-mail: robert.cerfolio@ccc.uab.edu).

J Thorac Cardiovasc Surg 2009;137:20-2

$0022-5223 / \$ 36.00$

Copyright (c) 2009 by The American Association for Thoracic Surgery doi: $10.1016 /$ j.jtcvs. 2008.08 .048
}

\section{REVIEW OF STILES AND ASSOCIATES' FINDINGS-MISCALCULATION OF THE T STATUS}

Stiles and colleagues ${ }^{1}$ found that PET was correct in predicting the T status as T1 in 192 of the $266(72 \%)$ patients and incorrect in the remaining $28 \%$. Interestingly, in our study, my colleagues and $\mathrm{I}^{5}$ found the $\mathrm{T}$ status to be incorrect in $47 \%$ of patients who underwent FDG-PET. Table 1 depicts these inconsistencies and also shows the clinical impact that the incorrect PET prediction had on patient care in the patients in Stiles and associates' study. In 52 $(20 \%)$ patients, the stage of disease was T2 as a result of visceral pleural invasion, and in $20(7.5 \%)$ patients, the disease stage was T4 as a result of satellite nodules. Two patients had $\mathrm{T} 3$ disease. Inasmuch as the preoperative and intraoperative therapy of all these patients would not have changed had the true pathologic $\mathrm{T}$ status been known before surgery, no patient received the improper therapy. The main reason this is true centers on the fact that the authors performed the correct operation: anatomic pulmonary resection with complete thoracic lymphadenectomy. However, could this statement be made if patients had undergone some of our new minimally invasive techniques that more and more patients are asking us to consider, for example, stereotactic radiotherapy or radiofrequency ablation or even videoassisted wedge resection? The answer is possibly no, especially for the first two therapies. Next, let us consider the misstaging that occurred with the nodal $(\mathrm{N})$ status.

\section{MISCALCULATION OF THE N AND M STATUS}

In their article, Stiles and colleagues ${ }^{1}$ found that the nodal or $\mathrm{N}$ status was wrong in $21(12 \%)$ patients and correct in $82 \%$ of the patients. Review of their results shows that 16 (7\%) patients had unsuspected N1 disease and 5\% had unsuspected $\mathrm{N} 2$ disease. In our prospective misstaging study, we $\mathrm{e}^{5}$ reported a $9 \%$, or almost double, incidence of unsuspected N2 disease compared with the authors' study. Again, we need to consider how the PET's misstaging hurt patient care. Inasmuch as the treatment of N1 or stage II disease is resection followed by adjuvant therapy, the 16 patients who had unsuspected N1 disease received no adverse therapy because of the PET's inaccuracy. Their care was the same, surgery followed by adjuvant therapy, as if their N1 status had been correctly identified preoperatively. This fact again is only true since Stiles and colleagues performed lobectomy in the vast majority of these patients and removed all of the regional N1 lymph nodes. Could the same statement be made if patients had undergone 


\section{Abbreviations and Acronyms}

$\mathrm{CT}=$ computed tomography

FDG = fluorodeoxyglucose

NSCLC $=$ non-small cell lung cancer

PET = positron emission tomography

stereotactic radiation, or radiofrequency ablation or even wedge resection? The answer is no.

Now we are left with only $13(5 \%)$ patients who had unsuspected $\mathrm{N} 2$ disease and $2(0.8 \%)$ who had unsuspected M1 disease from the same histologic cancer in another lobe. Recall that we started with 266 in the study and 97 were incorrectly staged. We have already shown that all but these 15 would have received the same care even if the PET had correctly staged the disease. Now let's consider the 13 patients with unsuspected (missed by PET) N2 disease. Perhaps these are the patients that one could argue had their care compromised because of the inaccuracies of the PET scan. This charge is easy to levy because many consider the best treatment of $\mathrm{N} 2$ disease to be preoperative chemoradiotherapy followed by careful restaging and surgical resection in properly selected patients. ${ }^{6}$ However, despite this claim, the truth is there are no data that show that patients with unsuspected or microscopic (PET negative $\mathrm{N} 2$ disease) disease fare better if given neoadjuvant therapy followed by resection, compared with resection followed by adjuvant therapy. Thus, once again it appears that patient care or therapy may not have been hurt because of PET's inaccuracies. Finally, we are left with only $2(0.8 \%)$ patients who had M1 disease from nodules palpated in the other lobes. As Bryant ${ }^{7}$ and I showed in 2008, if thoracotomy is used and the lobes that are not imaged to have nodules or masses in them are carefully palpated (which is difficult to do with video-assisted thoracic surgery), it is not uncommon to identify nonimaged nodules, some of which will be malignant. Although the clinical significance of these nodules is unknown, and thoracotomy with careful palpation of the lung tissue that is not planned to be resected, and then anatomic pulmonary resection of the cancer with complete thoracic lymphadenectomy is performed, patient care remains uncompromised. However, if lesser procedures are used, the patient may be left with unresected cancer and the preoperative misstaging is more likely to become clinically significant. Finally, some may argue that these lesser procedures may not hurt patient care because these other malignant areas (nodes or nodules) will grow and be discovered on postoperative surveillance at 3 or 6 months. Even if this claim is true, which is dubious, the patient has still lost the benefit of adjuvant therapy at the time of the initial treatment because his or her stage was not correctly identified. Moreover, the patient has to go through the added anxiety of another operation
TABLE 1. Review of data showing the lack of clinical impact on PET's misstaging in patients assumed to have stage IA NSCLC

\begin{tabular}{lccc}
\hline & $\begin{array}{c}\text { No. of } \\
\text { patients }\end{array}$ & $\begin{array}{c}\text { Types of misstaging } \\
\text { error by PET }\end{array}$ & $\begin{array}{c}\text { Impact on patient } \\
\text { care before surgery }\end{array}$ \\
\hline T status & 52 & T2 not T1 & None \\
& 20 & T3 not T1 & None \\
& 20 & T4 not T1 & None \\
N status & 18 & N1 instead of N0 & None \\
& 13 & N2 instead of N0 & None \\
M status & 2 & $\begin{array}{c}\text { M1 (same type of } \\
\text { malignant nodule } \\
\text { in other lobe) } \\
\text { instead of N0 }\end{array}$ \\
& & None & \\
\hline
\end{tabular}

PET, Positron emission tomography; NSCLC, non-small cell lung cancer.

and staging tests and the added cost of the procedure and its inherent morbidity. Thus, Stiles and coworkers' article, which highlights the understating of PET, shows that when intraoperative resection with lung palpation and complete thoracic lymphadenectomy is performed, the misstaging of PET does not seem to negatively affect patient care. However, what about the overstaging of PET?

\section{PROBLEM OF PET OVERSTAGING DISEASE}

Most critics would say that the real problem with PET comes with overstaging (false positives). The truth is that this is a problem only when physicians use poor judgment and treat patients using PET because "it lit up hot on PET" instead of performing careful tissue biopsy. We and others have shown that PET only provides targets and that biopsy specimens of these targets need to be obtained; therefore, the problem with overstaging does not lead to incorrect care. However, theoretically it could lead to unnecessary tests and procedures (ie, bone scan for false positive bone on PET, mediastinoscopy, endobronchial ultrasound, or endoscopic ultrasound/fine-needle aspiration for false positives lymph nodes). All these tests can be expensive, and there is morbidity with any procedure. The truth is that many surgeons perform mediastinoscopy routinely on all patients; if so, then the PET's misstaging again has not led to a change in patient care or any added cost.

Next, the critic might argue that PET scans light up the bone falsely or the liver falsely; therefore, bone scans are ordered unnecessarily, and tests to rule out adrenal metastasis are ordered as well. However, a large number of surgeons and physicians do bone scans routinely irrespective of the PET findings, and most CT scans cut down through the upper abdomen, allowing views of the liver and the adrenal glands in patients with a lung nodule. The truth again is that the expense added by PET scan is probably minor, even when it is falsely positive. Again, patient care is not compromised. Finally, some may argue that one should perform a mediastinoscopy, endobronchial ultrasound, and endoscopic ultrasound 
in all patients because they may help discover unsuspected N2 disease as described above. The clinical significance of this microscopic disease from the preoperative care of patients remains to be ascertained. Thus, we are now left with the question, "Then why do a PET at all?"

\section{ADVANTAGES OF PET SCAN}

If PET is inaccurate for patients thought to be in stage IA, and up to $30 \%$ are not, then why perform PET at all? There are many reasons, as shown by prospective studies. First, PET provides the best staging to rule out metastatic M1 disease. ${ }^{8}$ This leads to better patient selection and avoids thoracotomy and pulmonary resection that probably is not helpful. Second, PET is the best staging tool of the mediastinum, as shown by a multitude of studies. ${ }^{9-11}$ Third, it is the only test that provides the maximum standardized uptake value of the primary tumor. We and others have shown the importance of this in terms of surveillance, biologic aggressiveness, and perhaps the use of adjuvant chemotherapy. Moreover, its role for restaging after neoadjuvant chemoradiotherapy is critical. ${ }^{6}$ The percent change in the maximum standardized uptake value is the best tool to help guide patient therapy as well as monitor the response rate to treatments given. When neoadjuvant therapy is given, the change in the maximum standardized uptake value of both the primary tumor and the mediastinal lymph nodes is the best predictor of pathology. Therefore, although PET may be imperfect, it like all other tests has false negative results (as shown by Stiles and colleagues ${ }^{1}$ ) and false positive results. However, when physicians who are critical thinkers and experts in lung cancer interpret PET and then provide the appropriate care as guided by the PET findings, these misstaging errors rarely hurt patient care.

Although Stiles and colleagues ${ }^{1}$ have presented important data on the shortcomings of PET, as my colleagues and $\mathrm{I}^{5}$ did in 2005, the truth is that PET should remain a mandatory part of the preoperative evaluation of a patient with apparently resectable NSCLC. It remains the standard of care for these patients. If physicians would obtain biopsy tissue of all targets suggested by integrated PET/CT as well as by contrasted 5-mm cut CT scans instead of assuming cancer in the abnormal lesion, the stage, care, and survival of patients with NSCLC would be improved. Finally, and perhaps most important, if patients undergo pulmonary resection (with careful bimanual lung palpitation) along with complete thoracic lymphadenectomy, they receive outstanding care that maximizes their survival. However, if patients and physicians elect for lesser procedures, such as stereotactic radiation or radiofrequency ablation that does not remove all of the mediastinal lymph nodes, then patient care and survival are bound to suffer. The well-documented misstagings by PET, in particular false negative results, have to be considered if patients elect to undergo nondefinitive therapy.

\section{References}

1. Stiles BM, Lee PC, Servais EC, Port JL, Paul S, Meherally D, et al. Clinical stage IA lung cancer by CT and PET scan: the persistent problem of understaging. J Thorac Cardiovasc Surg. 2009;137:13-9.

2. Cerfolio RJ, Ojha B, Bryant AS, Raghuveer V, Mountz JM, Bartolucci AA. The accuracy of integrated PET-CT compared with dedicated PET alone for the staging of patients with nonsmall cell lung cancer. Ann Thorac Surg. 2004;78: 1017-23.

3. Shim SS, Lee KS, Kim BT, Chung MJ, Lee EJ, Han J, et al. Non-small cell lung cancer: prospective comparison of integrated FDG PET/CT and CT alone for preoperative staging. Radiology. 2005;236:1011-9.

4. Lardinois D, Weder W, Hany TF, Kamel EM, Korom S, Seifert B, et al. Staging of non-small cell lung cancer with integrated positron emission tomography and computed tomography. N Engl J Med. 2003;348:2500-7.

5. Cerfolio RJ, Bryant AS, Ojha B, Eloubeidi M. Improving the inaccuracies of clinical staging of patients with NSCLC: a prospective trial. Ann Thorac Surg. 2005; 80:1207-13.

6. Cerfolio RJ, Bryant AS, Ojha B. Restaging patients with N2 (stage IIIa) nonsmall cell lung cancer after neoadjuvant chemoradiotherapy: a prospective study. J Thorac Cardiovasc Surg. 2006;131:1229-35. Erratum in: J Thorac Cardiovasc Surg. 2006;132:565-7.

7. Cerfolio RJ, Bryant AS. Is palpation of the nonresected pulmonary lobe(s) required for patients with non-small cell lung cancer? A prospective study. J Thorac Cardiovasc Surg. 2008;135:261-8.

8. Erasmus JJ, Macaplinac HA, Swisher SG. Positron emission tomography imaging in non small-cell lung cancer. Cancer. 2007;110:2155-68.

9. Craanen ME, Comens EF, Paul MA, Smit EF. Endoscopic ultrasound guided fineneedle aspiration and 18FDG-positron emission tomography in the evaluation of patients with non-small cell lung cancer. Interact Cardiovasc Thorac Surg. 2007; 6:433-6.

10. Yasufuku K, Nakajima T, Motoori K, Sekine Y, Shibuya K, Hiroshima K, et al. Comparison of endobronchial ultrasound, positron emission tomography, and CT for lymph node staging of lung cancer. Chest. 2006;130:710-8.

11. Bryant AS, Cerfolio RJ, Klemm KM, Ojha B. Maximum standard uptake value of mediastinal lymph nodes on integrated FDG-PET-CT predicts pathology in patients with non-small cell lung cancer. Ann Thorac Surg. 2006;82:417-22. 